\title{
Analisis Visual pada Karakteristik Cosplay Berhijab
}

\author{
Anisa Nada Suksmono ${ }^{1 *}$, Andrian Dektisa Hagijanto ${ }^{2}$, Mendy Hosana Malkisedek ${ }^{3}$ \\ 1,2,3 Program Studi Desain Komunikasi Visual, Fakultas Seni dan Desain \\ Universitas Kristen Petra, Jalan Siwalankerto No. 121-131, Surabaya \\ "Penulis korespondensi; Email: anisanada@gmail.com
}

\begin{abstract}
Abstrak
Cosplay menjadi hobi cosplay diminati masyarakat Indonesia dari berbagai latar belakang agama, salah satunya adalah agama Islam. Islam memiliki aturan bagi muslimah (sebutan bagi wanita yang beragama Islam) untuk menutup aurat, salah satunya dengan menggunakan hijab. Untuk dapat melakukan cosplay berhijab terdapat muslimah yang mencampurkan visual figur anime, manga, dan game dengan hijab dan kostum yang dikenakan. Percampuran tersebut terlihat pada modifikasi kostum dan rambut figur yang dicosplaykan. Menggunakan konsep Hibriditas Homi K. Bhabha, modifikasi kain hijab dan kostum cosplay dilihat sebagai hibriditas visual sebagaimana kejelasan identitas cosplay dan hijab menjadi lebur dan menghasilkan sebuah identitas baru yakni cosplay berhijab. Penelitian ini adalah analisis deskriptif dengan sudut pandang memaknai fenomena visual cosplay berhijab sebagai satu bentuk upaya mencapai rasa percaya diri dan sebagai bentuk perayaan masyarakat poskolonial akan kebutuhan 'jaman now'. Untuk mencapai kedua hal tersebut, cosplayer berhijab melakukan modifikasi kain hijab dan kostum cosplay dengan tetap memasukkan karakteristik visual figur yang dicosplaykan.
\end{abstract}

Kata kunci: Cosplay Berhijab, Hibriditas Visual.

\begin{abstract}
Cosplay becomes a hobby that some Indonesians are interested in, including Indonesians who believe in Islam. Islam has regulations for its people, especially Muslim women, to cover their genitalia, one of which is by using the hijab. Therefore, to be able to do cosplay, they mixed visual figures from Japanese anime, manga, and games with hijab and cosplay costumes. The visual mixture is seen in the modification of the costume and figure's hair that is shown. Using Homi K. Bhabha's hybridity concept, hijab fabric and cosplay costume modification are seen as visual hybridity as the identity of cosplay and hijab dissolved and generate a new identity that is known to be hijab cosplay. This research is a descriptive analysis by using the perspective of interpreting visual phenomenon known as hijab cosplay as an effort to achieve self-confidence and as a form of celebration of the postcolonial society or today's need. To achieve those things, the hijabed cosplayer modifies hijab fabric and cosplay costume that still includes the visual attributes of the character that is being cosplayed.
\end{abstract}

Keywords: Hijab Cosplay, Visual Hybridity.

\section{Pendahuluan}

Cosplay merupakan fenomena menirukan impresi dari figur anime, manga, dan game yang berasal dari Jepang. Kata cosplay merupakan kata serapan bahasa Inggris yakni costume (pakaian yang dikenakan dalam kondisi tertentu) dan play (sebuah permainan yang merujuk pada aktivitas memerankan figur) sehingga secara bahasa cosplay dapat diartikan sebagai permainan kostum. Cosplay sendiri didefinisikan sebagai seni pertunjukan dimana cosplayer atau seseorang yang melakukan cosplay akan mengenakan kostum seperti tokoh manga dan anime serta memerankan karakter tokoh itu semirip mungkin dengan karakter aslinya. Seiring berjalannya waktu, kostum yang di-cosplaykan tidak hanya terbatas pada manga dan anime tetapi juga merambah ke game, drama Jepang, hingga figur original yang dibuat sendiri oleh cosplayer (Rastati, 2015).

Cosplayer (sebutan untuk pelaku cosplay) lebih senang mendefinisikan cosplay sebagai identifikasi diri mereka dengan figur-figur fiksi melalui kostum, aksesoris, riasan, hingga menirukan adegan-adegan figur yang sedang dicosplaykan untuk melengkapi penampilan mereka. Cosplay menjadi ajang unjuk diri cosplayer dengan mentransformasi tampilan semirip mungkin dengan figur anime, manga, 
dan game terutama pada kemiripan tampilan dan ekspresi wajah. Maka dari itu cosplay tidak lagi menjadi sekedar permainan kostum.
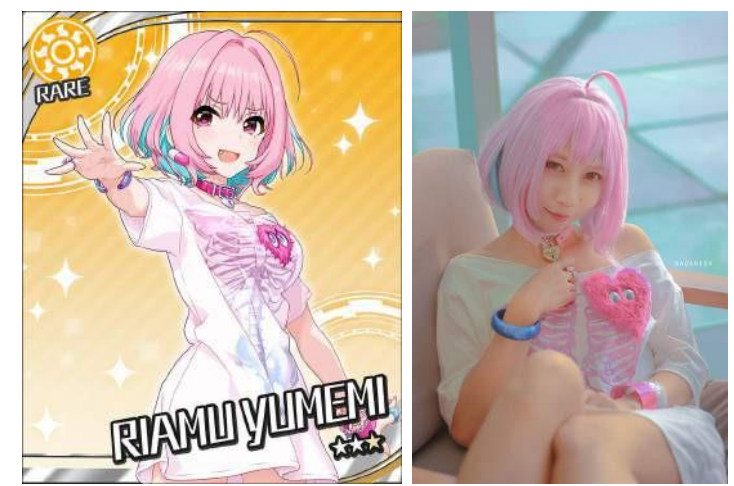

Gambar 1. Cosplay (Sumber : IDOLM@ASTER Cinderella Girls (2019); Dokumentasi Pribadi)

Widyatmoko (2013: 4) menjelaskan bahwa cosplay merupakan jenis tipe pertunjukan dimana cosplayer memakai kostum dan aksesoris untuk meniru figur tertentu. Menurut Jiwon (2008: 5), cosplay merupakan semacam kegiatan para penggemar anime dan manga yang dilakukan individu atau kelompok dengan membuat dan mengenakan kostum serta berdandan meniru figur tertentu dengan tujuan untuk tampil di depan publik. Cosplay berdasarkan jurnal Machademia (Winge, 2006: 65) dapat merujuk pada kegiatan seperti penyamaran diri yang diasosiasikan dengan berpakaian dan berperan seperti figur anime, manga, dan game, cosplayer juga mengeluarkan uang dan waktu dalam membuat kostum, mempelajari pose, dan dialog yang menjadi ciri khas figur yang akan dicosplaykan.

Untuk dapat disebut sebagai cosplay, terdapat tata cara bercosplay yang harus dilakukan oleh cosplayer berhijab. Cosplayer menggunakan wig dan lensa kontak untuk merubah tampilan mata dan rambut layaknya figur yang dicosplaykan, menggunakan kostum figur yang dicosplaykan, mengaplikasikan riasan wajah untuk memiripkan fitur-fitur wajah figur pada cosplayer, dan mempelajari ekspresi, gerakan, dan pose figur. Selama periode mengenakan kostum, ada cosplayer yang memilih tetap in character (tetap memerankan karakter figur) dengan cara bersandiwara menghayati karakter figur. Segala upaya tersebut dilakukan untuk menghasilkan impresi yang menyerupai figur yang dicosplaykan. Cosplay telah menjadi tren yang fenomenal dengan banyaknya acara dan kompetisi yang dikhususkan bagi para cosplayer. Antusiasme akan tren cosplay membuat banyak komunitas-komunitas cosplay didirikan sebagai tempat cosplayer untuk mencari teman dengan hobi yang sama dan meningkatkan keterampilan mereka dalam ber-cosplay.
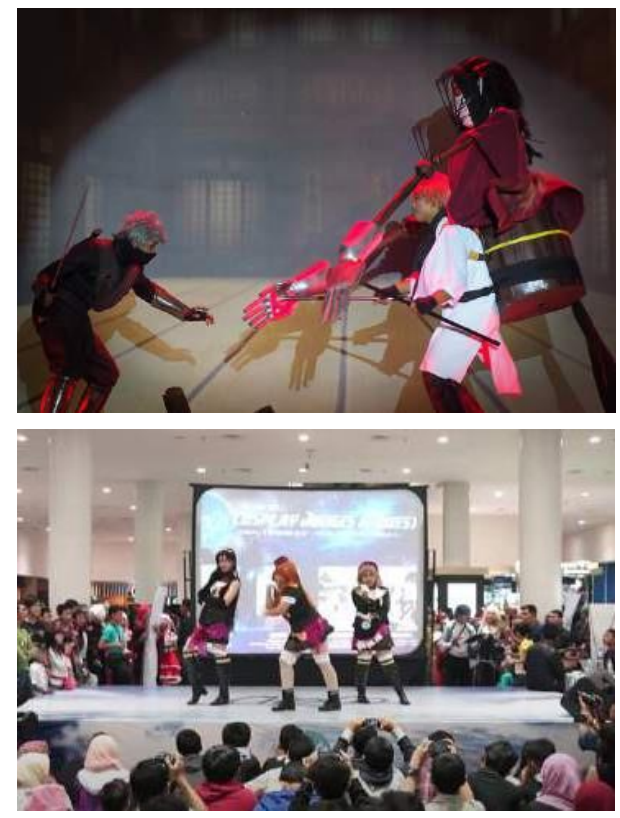

Gambar 2. Acara Cosplay (Sumber: Dokumentasi Ikimasu! (2020); Euponine (2015))

Hobi cosplay di Indonesia diminati oleh masyarakat dengan latar belakang agama yang berbeda-beda, salah satunya Islam. Islam memiliki batasan bagi kaumnya, terutama muslimah (kaum perempuan pemeluk agama Islam) untuk menutup aurat, yakni menutup seluruh anggota tubuh kecuali wajah dan telapak tangan. Salah satu tindakan dalam menutup aurat adalah dengan menggunakan hijab untuk menutupi aurat rambut. Untuk dapat melakukan cosplay ada muslimah yang memilih melepas hijabnya agar dapat bercosplay semirip mungkin dengan figur yang dicosplaykan dan ada pula muslimah yang memilih tidak melepas hijabnya ketika bercosplay tetapi mencampurkan visual figur yang dicosplaykan dengan kostum dan hijab yang dikenakan. Percampuran ini terlihat pada modifikasi kostum dan rambut figur. Kostum dengan menampilkan bagian yang terbuka dimodifikasi menjadi tertutup dan kerudung berwarna digunakan sebagai pengganti wig pada rambut figur. 


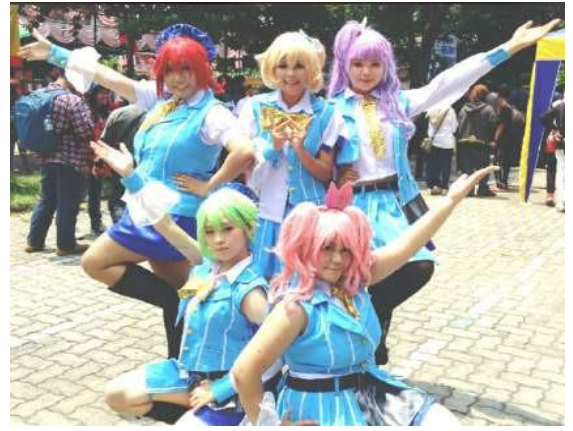

Gambar 3. Cosplay di Indonesia

Hijab atau Al-Hijab berasal dari kata hajaban yang dalam dalam bahasa Arab memiliki arti menutupi sesuatu. Abul Baqa' Al Hanafi juga menjelaskan bahwa setiap yang menutupi halhal yang ditutupi atau menghalangi hal-hal yang terlarang untuk digapai juga merupakan hijab. Diantara penerapan maknanya, hijab dimaknai dengan as sitr yang juga memiliki penutup untuk menghalangi sesuatu agar tidak bisa terlihat. Dalam Kamus Bahasa Indonesia, pengertian hijab adalah: tirai, tutup, penghalang, dan sebagainya. Dalam kamus ilmiah Burhani (2000), definisi kata hijab adalah suatu tirai atau tabir.

Ketentuan agama Islam tentang batas aurat perempuan disepakati berdasarkan firman Allah, hendaknya mereka (perempuan) tidak menampakkan perhiasannya kecuali anggota tubuh yang biasa tampak (Qs. Al-Nur:31) kemudian diulas oleh fuqaha (para ahli hukum Islam) dan disepakati bahwa yang dimaksud dengan aurat perempuan yaitu seluruh badan kecuali wajah dan kedua telapak tangan saja. Ibnus Abbas berkata, maksud anggota tubuh yang biasa tampak adalah wajah dan kedua tangan (Asna Al-Mathalib Fi Syarh Raudh AlThalib, p.176). Dalam konteks agama Islam, hijab lebih mengarah pada tata cara pemakaian penutup aurat perempuan yang pantas dalam tuntutan agama Islam. Aurat diartikan oleh Kamus Besar Bahasa Indonesia sebagai bagian-bagian yang tidak boleh diperlihatkan atau kemaluan sebagai alat perkembang biakan. Pada kalangan ulama Syafi'ah, pengertian aurat ialah tiap-tiap sesuatu yang memiliki nilai hukum dalam menutupnya, sedangkan dalam kalangan ulama Hanafiyah, pengertian aurat ialah sesuatu yang wajib ditutupi secara baik dalam segala keadaan sekalipun dalam keadaan sunyi terkecuali ada maksud tertentu.

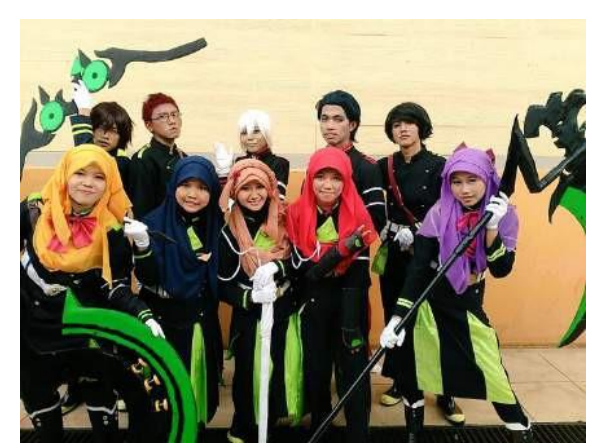

Gambar 4. Cosplay berhijab (Sumber: Koleksi dan Dokumentasi Islamic Otaku Community (2016))

Cosplay berhijab merupakan fenomena baru dalam acara budaya pop Jepang. Menurut Rastati (2015), fenomena cosplay berhijab ini muncul pada tahun 2012 dan semakin berkembang pada 2014. Cosplay berhijab melakukan percampuran tampilan cosplay dan hijab sehingga memunculkan identitas visual baru. Hal ini terjadi karena hobi cosplay dapat dinikmati oleh masyrakat dari latar belakang agama yang berbeda-beda, salah satunya Islam. Para muslimah ingin menyalurkan hobi cosplaynya tanpa perlu melepas hijab.

Berbeda dengan cosplay non hijab yang mengenakan kostum dan wig untuk mendapatkan tampilan yang menyerupai tokoh fiksi, cosplay berhijab menggunakan teknik tertentu seperti mengenakan kain hijab sebagai pengganti wig dan memodifikasi kostum agar menutup aurat. Modifikasi ini menciptakan sebuah tampilan visual yang berbeda dari cosplay pada umumnya. Cosplayer berhijab melakukan berbagai macam teknik modifikasi pada hijab untuk meniru bentuk rambut figur asli, seperti menguncir hijab, menyambung hijab, memendekkan hijab, mengepang hijab, dan membuat poni dengan hijab. Dari segi kostum dilakukan beberapa teknik seperti memanjangkan kostum untuk menutup ba-gian kulit dengan kaus panjang maupun celana panjang berwana selain warna kulit.

Cosplay berhijab mencari cara untuk dapat melakukan hobi cosplay tanpa melepas jilbab sehingga tercipta upaya untuk memodifikasi tampilan figur. Terdapat dua usaha yang dilakukan oleh cosplayer berhijab, yaitu mengubah penggunaan wig dengan hijab dan memodifikasi bagian kostum agar menutup kulit. 


\section{Metode Penelitian}

Metode penelitian yang digunakan adalah analisis deskriptif kualitatif atas objek material dengan teori hibriditas. Penelitian kualitatif adalah penelitian yang digunakan untuk meneliti pada kondisi objek alamiah, dimana peneliti merupakan instrumen kunci (Sugiyono, 2005). Penelitian kualitatif juga digunakan untuk memahami fenomena yang diamati subjek dengan cara mendeskripsikan dalam bentuk kata-kata dengan memanfaatkan berbagai metode alamiah (Moleong, 2007). Penelitian kualitatif dilakukan dengan studi literatur, menjabarkan aspek visual dengan analisis deskriptif, dan menghubungkan data dengan teori.

Selanjutnya dalam penelitian ini digunakan the site of image sebagaimana pada metodologi visual makna dapat dihasilkan oleh gambar itu sendiri, sehingga orang yang melihat sebuah gambar tertentu dapat memaknai lewat gambar. Dalam melihat suatu karya visual terdapat 3 sudut pandang yang dapat digunakan yaitu: the site of the image itself, the of the production of an image, dan the site where it seen by various audiencing (Rose, 2006: 16). Ketiga sudut pandang ini memiliki tiga tahapan proses analisis yang berkaitan dalam memaknai karya visual yang disebut dengan modalities. Ketiga modalities tersebut adalah technological, compositional, dan social. Sudut pandang site of the image itself dipilih karena dapat mempertimbangkan bagaimana gambar menciptakan makna yang juga dapat menghasilkan interpretasi visual.

\section{Pembahasan}

\section{Karakterisitik Visual Cosplay Berhijab}

Cosplay berhijab merupakan cara bagi muslimah berhijab dapat menyalurkan hobi cosplay tanpa perlu melepas hijab. Uniknya figur anime, manga, dan game Jepang yang dipilih untuk di-cosplay-kan berhijab tidak selalu memiliki busana yang menutup aurat perempuan. Agar figur-figur demikian dapat di-cosplay-kan berhijab, perlu dilakukan modifikasi. Modifikasi yang dilakukan cosplayer berhijab dapat didasari pada desain fanart figur anime, manga, dan cosplay yang sudah dihijab maupun mendesain sendiri tampilan modifikasi. Modifikasi pada cosplay berhijab dilakukan pada dua hal, yaitu kain hijab dan kostum cosplay.
Modifikasi pada kain hijab bertujuan menutup bagian rambut figur yang dicosplaykan, untuk itu kain hijab dimodifikasi agar menyerupai karakteristik rambut figur yang dicosplaykan. Karakteristik rambut figur yang dimaksud adalah warna rambut, gaya poni, gaya rambut samping, gaya rambut belakang, dan aksesoris rambut. Perlu digaris bawahi bahwa warna rambut merupakan karakteristik rambut figur yang wajib ditampilkan pada modifikasi kain hijab, sedangkan gaya poni dan gaya rambut bersifat opsional. Modifikasi pada kain hijab dapat dilihat pada (1) Pemilihan warna kain hijab yang sama seperti warna rambut figur yang dicosplay, dan (2) Hijab yang dikreasikan dengan teknik-teknik tertentu agar menyerupai gaya rambut figur yang dicosplay. Teknik-teknik dalam mengkreasikan hijab yaitu mengikat kain hijab dengan karet untuk menguncir maupun mengepang hijab dan menggunakan alat bantu peniti maupun jarum pentul untuk memendekkan kain hijab dan mengkreasikan poni.

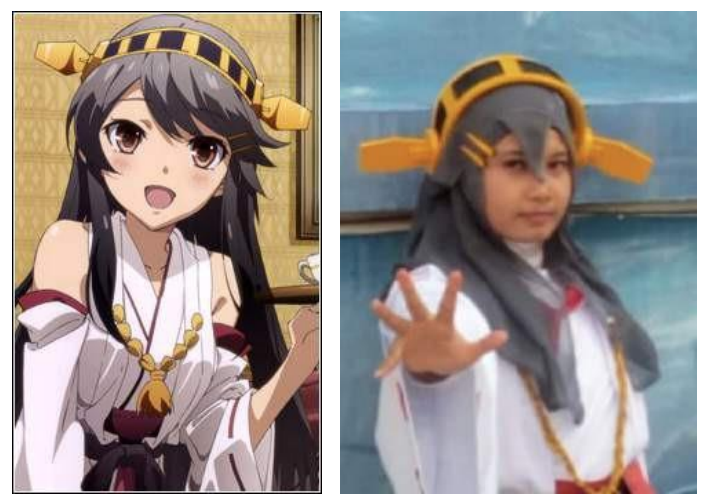

Gambar 5. Modifikasi pada Kain Hijab (Sumber: MyAnimelist (2015); Koleksi Rara Uzuki (2019))

Modifikasi pada kostum cosplay bertujuan menutup bagian kulit figur pada kostum. Akan tetapi terdapat beberapa hal menyangkut karakteristik visual kostum yang harus diperhatikan cosplayer berhijab ketika memodifikasi kostum cosplay. Berdasarkan pengamatan terdapat karakteristik visual kostum yang dapat dimodifikasi dan yang tidak dapat dimodifikasi. Untuk menutup bagian kulit figur diperbolehkan memodifikasi jenis kostum, misalnya figur yang menggunakan celana pendek dimodifikasi dengan menggunakan rok panjang. Agar rok panjang tersebut masih dapat dikenali sebagai kostum dari 
figur tertentu, tidak diperkenankan melakukan modifikasi pada komposisi warna kostum, ornamen kostum, dan aksesoris pada kostum. Akan tetapi modifikasi pada ornamen dan aksesoris kostum masih dapat dilakukan bila memiliki desain yang menyerupai ornamen maupun aksesoris agama selain Islam, contohnya ornamen maupun aksesoris berbentuk salib. Ketika dihadapkan pada desain kostum yang demikian, cosplayer berhijab diper-kenankan memodifikasi ornamen atau aksesoris kostum yang berbentuk salib men-jadi bentuk plus (+). Dengan memperhatikan karakteristik kostum yang dapat diubah dan tak dapat diubah, diharapkan kostum figur yang telah dimodifikasi tetap dapat dikenali.

Terdapat dua teknik dalam cara cosplayer berhijab memodifikasi tampilan kostum, yaitu:

a) Memanjangkan kain pada bagian tertentu kostum agar menutup bagian kulit figur yang tampak, contohnya kostum figur yang berlengan pendek dimodifikasi menjadi berlengan panjang, kostum figur yang menggunakan celana pendek dimodifikasi dengan menggunakan rok, atau bahkan kostum figur yang menggunakan jaket dan bercelana pendek dimodifikasi menggunakan gaun yang berlengan panjang dan ber-rok panjang.

b) Menggunakan kostum sesuai desain asli kostum figur yang dicosplaykan namun terdapat penggunaan celana panjang maupun kaos panjang untuk menutupi bagian kulit figur yang masih terlihat. Contohnya figur yang memiliki kostum berlengan pendek tidak perlu dirubah menjadi kostum berlengan panjang, cukup dengan menutupi bagian kulit lengan yang tampak dengan kaos panjang. Pada teknik ini, kebanyakan cosplayer menggunakan celana panjang maupun kaos panjang berwarna putih atau hitam.

Hingga artikel ini ditulis, belum terdapat pembaruan teknik cosplayer berhijab Indonesia dalam modifikasi tampilannya.

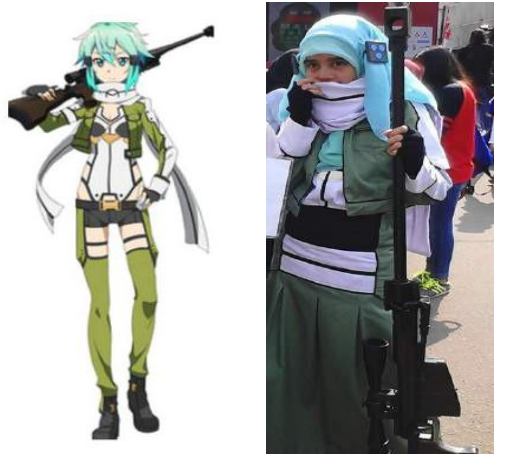

Gambar 6. Modifikasi pada Kain Hijab (Sumber: Sword Art Online Code Register (2014); Koleksi Islamic Otaku Community (2015))

\section{Bagaimana Cosplay Berhijab Bercampur}

Cosplay berhijab merubah tampilan karakter yang seharusnya tidak berhijab menjadi berhijab. Walaupun begitu, figur anime, manga, dan game yang dicosplaykan berhijab tidak boleh menghilangkan karakteristik visualnya sehingga akan tetap dapat dikenali sebagaimana figure yang sedang dicosplaykan. Fenomena visual yang men-campurkan dua budaya visual dianalisis dengan menggunakan teori hibriditas. Teori hibriditas Homi K. Bhabha menjelaskan interaksi antara bentuk-bentuk budaya yang berbeda sehingga menghasilkan identitas baru. Hasil dari identitas baru memiliki kemiripan bentuk tetapi tidak menghasilkan bentuk identik seperti identitas yang ditiru, proses ini dikenal sebagai mimikri. Mimikri menghasilkan kondisi yang ambivalensi karena harus menampilkan dua identitas yang berbeda

Cosplayer memerankan figur anime, manga, maupun game dengan menggunakan atribut-atribut seperti wig, kostum, aksesoris, dan riasan wajah digunakan untuk menirukan figur anime, manga, game. Impresi dari atribut digunakan menciptakan kesan semirip mungkin dari figur yang dicosplaykan. Oleh karena itu, cosplayer menampilkan dirinya menjadi berbeda dengan kondisi tanpa cosplay, sehingga tak jarang tampilan yang disajikan sangat kontras dengan tampilan sehari-hari ketika berhijab. Tampilan cosplay yang terkadang memiliki kesan 
aneh dan nyentrik dapat memunculkan berbagai reaksi, khususnya dari penikmat cosplay. Misalnya ajakan untuk foto maupun video bersama atau melakukan project cosplay bersama. Reaksi yang berbentuk kekaguman dan sikap-sikap apresiatif pada tampilan cosplay berhijab sering menciptakan rasa percaya diri dari si cosplayer berhijab. Tampilan cosplay berhijab dirasa memiliki tampilan yang menarik dan dapat menciptakan berbagai kesan seperti keren, imut, dan lain sebagainya tanpa harus mengekspos tampilan sebenarnya dari cosplayer berhijab (Nugroho, 2014).

Kesan mendalam atas impresi cosplay mendorong muslimah berhijab untuk cosplay, tetapi sebagai muslimah berhijab terdapat syariat untuk menutup aurat. Keinginan untuk mencoba tampilan cosplay sangat kuat sehingga dilakukanlah pencampuran kain hijab dengan elemenelemen visual cosplay. Ketika hijab dan cosplay "bersatu" menghasilkan hibrid maka hijab akan memunculkan sifat-sifat tertentu dari hijab dan cosplay sekaligus meniadakan sifat-sifat tertentu yang dimiliki keduanya dan dimaknai sebagai hibriditas. Menurut Bhabha (1994), hibriditas terjadi ketika batasan-batasan yang terdapat di sebuah identitas mengalami pelenturan, sehingga kejelasan identitas budaya menjadi lebur dan menghasilkan sebuah identitas yang baru. Karakteristik hibrid dalam cosplay berhijab meliputi:

\section{a) Tampilan cosplay}

Cara cosplayer dalam menampilkan kostumnya tidak fleksibel dan bukan menuruti kehendak sendiri. Oleh karenanya, tampilan cosplay harus mengikuti pakem dan dibuat benarbenar mirip layaknya figur yang dicosplay-kan. Hal tersebut kontras dengan tindakan para muslimah yang melakukan modifikasi pada tampilan cosplay agar menciptakan peluang untuk melakukan cosplay tanpa melepaskan hijab. Kostum cosplay yang seharusnya dibuat semirip mungkin dengan kostum yang digunakan oleh figur anime, manga, maupun game harus dimodifikasi untuk menutup bagian kulit. Wig yang seharusnya menampilkan gaya rambut figur anime, manga, maupun game juga harus dimodifikasi dengan kain hijab. Tampilan cosplay berhijab dapat di- katakan mengalami pelenturan dengan adanya berbagai modifikasi visual.

b) Kain hijab yang digunakan pada cosplay berhijab

Hijab seringkali dipandang sebagai simbol agama yang melambangkan tindakan manusia untuk menjauhkan diri dari keinginan duniawi. Penggunaan hijab pada cosplay berhijab mengalami modifikasi hijab yang semula sebagai "simbol agama" menjadi penutup aurat. Hijab yang digunakan dalam cosplay adalah sesuatu yang fleksibel karena dapat dimodifikasi. Kain hijab yang sebelumnya dipandang sebagai simbol agama dimodifikasi sedemikian rupa dalam cosplay menjadi ungkapan karya cosplay. Dengan begitu kain hijab yang digunakan pada cosplay berhijab lebih dilihat sebagai ekspresi dan juga dapat menjadi salah satu ambiguitas karena hijab dan cosplay "bersatu" menghasilkan hibrid.

Sifat relasi dan resistensi yang terjadi didalam ruang liminalitas merupakan taktik dan strategi kebudayaan, dimana pen-campuran budaya muncul atas batas wacana mapan dan produk budaya hibrid menggoyahkan batas tersebut dengan oposisi biner. Cosplay berhijab menggoyahkan Batasan hijab dan aturan tampilan cosplay. Hijab yang semula merupakan syariat agama dapat dinikmati sebagai bentuk kreativitas dalam cosplay berhijab dan muslimah dapat menyalurkan hobi bercosplay tanpa melepaskan hijab. Meskipun begitu, dalam memodifikasi tampilan cosplay tetap mempertahankan karakteristik visual figur yang dicosplaykan sehingga figur yang dicosplaykan akan dikenali.

Salah satu indikator keberhasilan cosplay terletak pada kemiripan tampilan cosplay dengan figur yang di-cosplay-kan. Cosplay yang awalnya hanya berupa permainan kostum berubah menjadi ajang kontes impresi menirukan karakter figur yang dicosplaykan. Ini menjadi semacam kecenderungan yang dilakukan cosplayer berhijab agar menampilkan karakteristik visual figur yang dicosplaykan selagi memodifikasi. Penyertaan karakteristik visual figur pada tampilan modifikasi dapat menampilkan impresi figur yang me- 
nyerupai figur anime, manga, dan game yang sedang dicosplaykan sehingga dapat diterima sebagai cosplay. Tindakan modifikasi pada cosplay berhijab adalah upaya agar diakui tidak melanggar syariat Islam dan tidak keluar dari tata cara cosplay dan dapat dimaknai sebagai mimikri.

Menurut Bhabha (1994: 86) mimikri adalah suatu hasrat dari subjek yang berbeda menjadi subjek yang hampir sama tetapi tidak sepenuhnya. Mimikri pada cosplay berhijab nampak dari modifikasi kain hijab dan kostum. Mimikri pada cosplay berhijab juga relevan dengan mimikri yang dikonsepkan menurut Bhabha dimana dilakukan oleh kelompok koloni agar menjadi bagian dari colonial. Mimikri adalah konsep yang berasal dari kajian poskolonial. Poskolonial merupakan paham yang menjadi legitimasi barat dalam menaklukkan timur. Timur dianggap tidak beradan, bodoh, dan terbelakang. Oleh karenanya barat datang untuk memberadabkan timur dengan tata cara dan budaya barat yang diyakini lebih maju. Timur dipaksa meniru menjadi barat, sebagai akibatnya timur menjadi tidak percaya diri karena harus selalu diberi sesuatu untuk dicontoh. Ketika eksistensi barat sudah tidak ada lagi di timur, timur menjadi bingung karena terbiasa diberi sesuatu untuk dicontoh. Hal tersebut menjadi timur tidak percaya diri dan selalu mencari contoh- contoh yang berasal dari luar.

Jejak-jejak inferiority juga dimaknai pada cosplayer berhijab ketika cosplay berhijab memimikri elemen visual cosplay ala Jepang dan budaya hijab Arab. Elemen visual cosplay Jepang yang terdapat pada karakteristik visual figur anime, manga, dan game ditampilkan dengan sentuhan modifikasi. Hijab sebagai elemen visual arab tidak dapat dilepas cosplayer berhijab, sehingga dilakukan peniruan gaya rambut figur yang dicosplaykan pada kain hijab. Bentuk hijab yang meniru gaya rambut figur yang dicosplay dan modifikasi kostum tanpa menghilangkan karakteristik visual figur yang dicosplay merupakan ungkapan mimikri pada cosplay. Sementara penggunaan figur anime, manga, dan game Jepang digunakan untuk mencapai rasa percaya diri sebagai upaya terapi psikologis pada rasa rendah diri.
Dalam memperoleh rasa percaya diri, apresiasi dari penonton impresi cosplay berpengaruh besar pada cosplayer berhijab. Tetapi terkadang cosplayer berhijab justru mendapatkan depresiasi dari penonton impresi cosplay. Depresiasi yang dimaksud adalah tidak adanya penikmat cosplay yang mengenali figur anime, manga, dan game yang sedang dicosplaykan oleh cosplayer berhijab, tidak adanya penikmat cosplay yang mengajak foto, dan tidak adanya apresiasi verbal dari penikmat cosplay. Berangkat dari pengalaman tersebut, cosplayer berhijab memiliki kecenderungan untuk memilih figur anime, manga, dan game yang sedang populer.

Pada konsep mimikri Bhabha yang direlasikan dengan poskolonial, kaum terjajah meniru penjajah tetapi juga tidak bisa melepaskan karakteristiknya sebagai terjajah sehingga tercipta kondisi kebingungan (ambivalensi). Ketika muslimah berhijab di satu sisi ingin melakukan cosplay, di sisi lain memungkinkan munculnya resistensi. Bentuk resistensi yang dimaksud adalah melepas hijab atau disisi lain "merusak cosplay. Cosplay berhijab dimaknai sebagai bentuk pencampur adukkan sehingga menciptakan kebingungan. Apakah cosplayer berhijab tetap menggunakan hijab mengikuti kaidah agama atau mengikuti tata cara cosplay sebagai bagian dari budaya pop namun tidak dapat meninggalkan penggunaan hijab. Disitulah tampilan cosplay berhijab tidak lagi murni menampilkan hijab maupun murni menampilkan cosplay. Kebingungan identitas yang dihasilkan cosplay berhijab juga dapat dilihat sebagai usaha cosplayer berhijab mencapai rasa percaya diri, walaupun rasa percaya diri tersebut hadir hanya ketika menjadi figur anime, manga, dan game.

Ketika hijab digunakan bersama dengan cosplay menjadi fenomena hibriditas yang menciptakan kebingungan (ambiguitas). Ambiguitas pada cosplay berhijab juga dimaknai pada modifikasi yang dilakukan antara cosplay dengan hijab yang muncul dan dianggap sebagai fashion. Perpaduan antara hijab dengan cosplay yang menghasilkan fashion menjadi sesuatu yang digemari sehingga banyak ditiru dan banyak dilakukan oleh anggota-anggota komunitas / kelompok. Hal ini sama seperti yang dikatakan oleh Troxell (1981), bahwa 
Fashion merupakan gaya yang diterima dan digunakan oleh ma-yoritas anggota kelompok dalam satu waktu tertentu. Fashion juga merupakan sistem tanda dimaknai sebagai sesuatu yang dapat mengkonstruk nilai-nilai budaya dari cara berpakaian (Barthes, 1990). Dengan begitu identitas seseorang dapat dilihat dari pakaian yang sedang dikenakan dan kemudian menjadi salah satu ambiguitas.

Ambiguitas pada cosplay berhijab dapat terlihat dari karakteristik hibriditas yang tercipta dari hijab dan kostum cosplay. Cosplay yang dihijab adalah modifikasi dan menjadi hibrid atas figur yang berasal dari dunia hiperealitas. Hijab yang diaplikasikan menurut karakteristik cosplay menjadi sesuatu yang mudah sekali berubah dan berpotensi mengabaikan syariat. Cosplay bukan merupakan fashion karena mengikuti tata cara berpakaian sebagaimana figur anime, manga, dan game yang diacunya sehingga tidak bisa digantikan dengan kain hijab walaupun direkayasa sedemikian rupa misalnya mengikuti gaya rambut, desain kostum, dan lain-lain. Tampilan cosplay yang dimodifikasi dengan hijab menjadi sebuah fashion, sehingga figur anime, manga, dan game yang dicosplaykan menggunakan hijab tidak lagi mengikuti tata cara cosplay tetapi menjadi sesuatu yang mudah berubah sesuai selera. Itulah juga yang dimaknai sebagai keadaan ambivalen.

Segala sesuatu yang digunakan oleh cosplayer berhijab merupakan perjuangan mendapatkan rasa percaya diri. Cosplayer berhijab adalah orang Indonesia yang merupakan bagian dari masyarakat poskolonial, sehingga secara tidak sadar melestarikan rasa rendah diri yang turun temurun. Layaknya masyarakat poskolonial, cosplayer berhijab membutuhkan contoh diluar dirinya untuk menghapus rasa rendah diri. Cosplayer berhijab sebagai muslimah di Indonesia tidak percaya diri dengan identitas lokalnya, sehingga membutuhkan identitas "kemuslimahan" yang berasal dari budaya Arab. Disisi lain cosplayer berhijab merupakan masyarakat konteporer yang menggemari budaya cosplay Jepang tetapi tidak cukup percaya diri untuk merayakan kekontemporerannya dengan melepas hijab, disisi lain juga tidak cukup percaya diri untuk menampilkan cosplay sesuai tata cara cosplay. Untuk menutupi rasa rendah diri sebagai masya- rakat poskolonial Indonesia, muslimah berhijab membutuhkan "baju zirah" cosplay berhijab, walaupun mendapatkan pertentangan dari kelompok muslim yang menggunakan identitas Arab dan kelompok cosplayer yang bercosplay mengikuti pakem.

\section{Simpulan}

Karakteristik cosplay berhijab ditampilkan dengan elemen visual Arab dan elemen visual Jepang. Elemen visual Arab terdapat pada penggunaan kain hijab dan elemen visual Jepang ditampilkan pada karakteristik figur anime, manga, dan game. Cosplayer berhijab menggabungkan kedua elemen tersebut dengan melakukan modifikasi. Modifikasi pada cosplay berhijab dilakukan dengan cara merubah tampilan cosplay mengikuti ketentuan penggunaan hijab tetapi juga menyertakan karakteristik visual figur anime, manga, dan game. Dengan melakukan modifikasi cara demikian cosplay berhijab dapat menampilkan impresi yang mirip dengan figur yang sedang dicosplay, sehingga figur anime, manga, dan game yang sedang dicosplaykan berhijab dapat dikenali.

Cosplay berhijab terjadi ketika muslimah berhijab mencampurkan hijab dengan cosplay. Cosplayer berhijab sebagai orang Indonesia merupakan masyarakat poskolonial, dan senantiasa mencari hal-hal lain sebagai pemuas dan 'upaya pemenuhan' atas hal tersebut. Hal-hal yang dipakai sebagai upaya mencari rasa percaya diri berasal dari luar dirinya, misalnya budaya hijab Arab dan budaya cosplay Jepang, sehingga secara tidak sadar mewarisi rasa rendah diri. Cosplayer berhijab membutuhkan identitas-identitas di luar identitas dirinya untuk mencapai rasa percaya diri. Sebagai muslimah indonesia, cosplayer berhijab tidak percaya diri untuk menampilkan identitas muslim yang tidak meniru budaya arab. Di sisi lain cosplayer berhijab merupakan masyarakat kontemporer yang menyenangi budaya pop Jepang dan ingin merayakan kekontemporerannya dengan bercosplay menurut budaya Jepang. Cosplayer berhijab merasa tidak percaya diri untuk melepaskan hijabnya untuk dapat bercosplay, di sisi lain merasa tidak percaya diri untuk melakukan cosplay sesuai pakem cosplay. Untuk menghapus ketidakpercayaan diri dan tidak meniadakan salah satu dari hijab maupun cosplay, terjadilah percampuran hijab dan cosplay yang juga dimaknai sebagai upaya menciptakan rasa percaya diri. 
Cosplay berhijab merupakan fenomena yang menarik untuk diteliti dan kaya akan objek penelitian. Dengan begitu penelitian bertema cosplay berhijab selanjutnya dapat mengembangkan objek material, seperti meneliti cosplayer berhijab yang menggunakan figur antagonis, figur seksi, figur laki-laki, figur superhero, dan figur Idol. Dari sisi cara mencampurkan cosplay dengan hijab dapat diteliti lebih dalam mengenai cosplay berhijab yang juga mencampurkan budaya lokal. Penelitian bertema cosplay berhijab selanjutnya juga dapat meneliti cara komunitaskomunitas cosplay berhijab berkomunikasi, seperti media sosial yang digunakan dan ornamen-ornamen tertentu yang mungkin digunakan dalam kostum untuk penciptaan identitas sebagai visual communication tools. Objek formal pada penelitian cosplay berhijab selanjutnya dapatmenggunakan teori selain hibriditas untuk mengkaji cosplay berhijab. Contohnya menggunakan teori hiperealitas, semiotika, dan crossculture. Sudut pandang dalam meneliti cosplay berhijab juga dapat dikembangkan menurut hukum islam, fashion, sinkretisme mashab Arab dan Japanofilia, keilmuan psikoanalisis, estetika, dan impresi cosplayer dalam menciptakan kesan-kesan tertentu.

\section{Daftar Pustaka}

Al-Islam, et al. 926H, Asna Al-Mathalib.

Barthes, R. 1990, The Fashion System, University of California Press, Berkeley CA.

Bhabha, H. K. 1994, The Location of Culture, Routledge, London and New York.
Japanese Station Staff. 2017, Cosplay Hijab di Kalangan Wanita Tanpa Perlu Melepas Jilbab, Unik Ya!, Diakses 24 Januari 2020, japanesestation.com/ cosplay-hijab-di-kalangan-wanita-muslimtanpa-perlu-melepas-jilbab-unik-ya/

Jiwon, A. 2008, Animated Subjects: Globalization, Media, and East Asian Cultural Imaginaries, Toward a Perfect Cosplay: Conversation With A Few Japanese Cosplayer, Disertasi, University of Southern California.

Moleong, L. J. 2007, Metodologi Penelitian Kualitatif, Remaja Rosdakarya, Bandung.

Nugroho, R. 2014, Ekspos: Apa salah dan Dosa Cosplay Hijab, Diakses 25 Januari 2020, https://www.kaorinusantara.or.id/newslin e/13002/mengenal-cosplay-hijab

Rastati, R. 2015, Dari Soft Power Jepang Hingga Hijab Cosplay, Jurnal Masyarakat \& Budaya, Vol. 17, No.3, p 373. https://doi.org/10.14203/jmb.v17i3.326

Rose, G. 2006, Visual Methodologies: An Introduction to the Interpretation of Visual Material, SAGE Publications Ltd, London.

Sugiyono, G. 2005, Memahami Penelitian Kualitatif, CV Alfabeta, Bandung.

Troxell, M. D. 1981, Fashion Merchandising, Gregg Division McGraw-Hill Book Company, New York.

Widyatmoko, B. 2013, Amazing Cosplay \& Costume Ideas, Penebar Plus, Jakarta.

Winge, T. 2006, Mechademia Vol 1: Emerging World of Anime and Manga. Costuming the Imagination: Origin of Anime and Manga Cosplay, University of Minnesota Press, United States. 